\title{
Literatura como uma arte da memória
}

\author{
Renato Janine Ribeiro
}

Como se articulam memória e literatura? Para o leigo e para boa parte dos profissionais, literatura tende a ser ficção. É lugar da imaginação, não da memória - e isso apesar de uma parte razoável da tradição ter ligado o que é imaginar ao que é recordar ${ }^{1}$. Em que pese a possível proximidade da memória e da criação literária, um recorte bastante bem sucedido distingue, nas colunas de livros mais vendidos que aparecem nos jornais mas também na prática acadêmica, o que é ficção do que é não-ficção. Por exemplo, se na organização acadêmica formos distinguir os cursos de letras dos de filosofia e de ciências humanas, diremos que esses últimos têm por assunto mais a não-ficção e, aqueles, mais a ficção. Contudo, o próprio fato de se tratar de uma instituição acadêmica implica que a obra mesma dos professores de letras seja de não-ficção. São raros, como Silviano Santiago, os que militam nas duas áreas. A questão se torna mais candente quando saímos das letras e vamos para as artes. O professor de artes é alguém que fala sobre as artes ou que as far? É um crítico ou um artista? Note-se que, no financiamento à pesquisa, é raro se pagar ao artista para que faça arte, e inexistente pagar-se a alguém para que se torne escritor ${ }^{2}$. A memória, estando do lado da não-ficção, parece ter mais parte com a ciência, a crítica, o que é sério; já a literatura dependeria da imaginação, do jogo.

Este início não destoa do que se segue. O caso da arte é exemplar, porque articula de maneira bastante explícita o que em outros setores do conhecimento fica implícito. $O$ próprio do ensino é formar o aluno, o que se faz sobretudo mediante a palavra oral, circulando entre professor e estudante. O próprio da pesquisa é transmitir o que ela tem de melhor, o que se faz sobretudo mediante a palavra que adquiriu permanência, que se tornou independente do seu autor, em suma, que foi impressa ou, hoje, oferecida ao público em meio eletrônico. A formação se dá no tête-à-tête, preferencialmente. Nada substitui a presença. Sim, o virtual cresce e, com ele, as redes: ensino, amizade e sexo fazem-se, com distintos graus de êxito, à distância. Mas há algo na presença que é insubstituível e que é da ordem do afeto: como posso formar um aluno se ele, pelo menos enquanto jovem, não puder comigo se identificar, a mim se opor? Isso é diferente da letra impressa. A publicação significa que a obra vai contribuir para quem está distante e, também, abrir-se a seu escrutínio, a seu debate, a sua contestação. Meu aluno me admira e me contesta, meu leitor também: mas de formas bem diferentes, e a diferença reside no investimento afetivo, maior na relação docente do que na leitura. (Tanto é assim que fica difícil entender o caso, raro mas real, de quem odeia um autor a quem nunca viu, de quem desenvolve um forte sentimento de aversão calcado, só, em palavras lidas.)

Ora, no caso da arte como fica a palavra? Distinguimos acima a palavra dita e a registrada, a que perece e a que permanece - mas como é isso nas artes? Muitos defendem que uma tese em artes possa incluir uma obra de arte, mas deva anexar um comentário. A banca haverá de falar sobre o trabalho. Não é uma questão já decidida, em nossa cultura. Não está sequer claro que um bom artista deva ter um doutorado, para poder depois 
formar suas pessoas. Mas o ponto a destacar é que, implicitamente, a mesma questão está presente em muitas áreas. Tomemos a medicina. Publicar artigos é contribuir para a pesquisa. Mas uma cirurgia, o que é? Ela não é considerada pesquisa, porque não está exposta ao distante, ao escrutínio remoto de que anteriormente falei; mas participar dela, ou de uma ação que gera um diagnóstico, pode ser decisivo para a formação do profissional e mesmo do pesquisador.

Voltemos às letras. O que distingue o crítico do escritor? Formamos críticos, sim, mais do que escritores (eis uma distinção significativa em face das artes). Silviano Santiago constitui exceção, não regra. Umberto Eco foi, mais que uma exceção, quase um escândalo, ainda que bem visto. Quando ele, crítico consagrado, autor de livros de referência que marcaram toda uma época - penso, antes de mais nada, em Apocalípticos e integrados - decidiu escrever $O$ nome da rosa, o impacto foi enorme. A crítica acolheu-o com simpatia. Poderia fazer de outro modo? Não aludo apenas às qualidades do livro. Um crítico de quatro costados poderia ser criticado acerbamente? E no entanto nada assegura que um crítico seja bom autor - tanto assim que a maior parte dos críticos não escreve ficção nem poesia.

Daí, uma relação tensa entre o crítico e o artista: Fellini até enforca seu crítico, em 8 1 \% É um homem insuportável, com sotaque que soa francês, uma espécie portanto de redator dos Cabiers du cinéma, a determinar o que o cineasta deve ou não fazer, condenando-o em nome de valores que nada têm a ver com a qualidade artística - e esse é o ponto essencial. Ele impõe à arte um papel platônico, rousseauniano: o seu valor estaria fora dela. Seu valor residiria na sua contribuição, ou não, para o mundo em crise em que vivemos. É essa atitude do crítico que o torna odioso a nosso tempo, que não suporta mais que na pólis de Platão não haja lugar para o poeta. Por isso, ele merece o ridículo e, depois, a pena igualmente risível a que é condenado. E no entanto esse julgamento meio político, meio moralista, que o infeliz crítico quer, não está longe do que o próprio Fellini pretende no filme. Afinal, o que é 8 1/2? Muito se discutiu esse nono filme, que ficou pela metade: daí, aliás, a explicação usual para seu título. A questão, porém, é: o que seria o filme se tivesse sido rodado e concluído?

$\mathrm{Na}$ bibliografia que conheço sobre $81 / 2$ nada disso se ressalte; não encontrei ninguém a perguntar qual seria o filme por trás do filme. Estão claros, penso, apenas três pontos. O primeiro é que, ao fim da película, não se podendo sobreviver na Terra, os personagens deixam-na num foguete rumo ao espaço. Portanto, a conclusão deveria ser a de que nossa vida, aqui, é insustentável: ou de que nossa vida é insustentável. O segundo ponto, que antecede o primeiro porque perpassa todo o filme, é uma indagação sobre o sentido da vida, que leva o cineasta até mesmo a consultar um monsenhor, por sinal para completa frustração sua. O terceiro é a pureza, residindo na personagem de Claudia Cardinale, que porta a água que vivifica. Em suma, teríamos uma pergunta sobre o valor da vida, que conclui que esta é insustentável, talvez porque o personagem não saiba amar, não saiba aceder à pureza. Esse parece ser o filme raté, o filme que deveria ter existido mas não veio à luz.

Mas qual é a relação entre o filme que não deu certo (o nono) e aquele que, apesar de ser chamado um filme pela metade, apesar de registrar o fracasso do filme planejado, é possivelmente a obra em que Fellini decola, em que se torna realmente um gênio, em que 
gera sua provável maior obra-prima? Em que pontos o filme de fato destoa do filme inicialmente desejado? Procuremos responder. O primeiro ponto é o valor da vida, que passa a consistir sobretudo na relação com as mulheres. Ou seja, a grande questão do nãofilme se torna, no filme possível ou pelo menos realizado, mais precisa. No filme planejado, o sentido da vida estaria na metafísica ou na religião; no filme a que assistimos, ele está na possibilidade de se ter uma relação (boa? decente? feliz?) com uma mulher. Ora, geralmente, focando-se o problema, tendemos a supor que ele se torne mais fácil de solucionar; mas não é esse o caso, aqui, ou pelo menos não parece assim ser. Saiu-se da grande e infecunda abstração, que culminava na conversa com o prelado - um diálogo sem resposta, um monólogo sem resultado -, para se chegar à concreção precisa, mas fracassada: o impasse. Avançou-se, aprofundou-se, mas nada foi resolvido.

O filme feito também destoa do filme sonhado no papel da memória. Cenas do passado - a relação com a mãe, com a avó reprimida e repressora, com o avô corajoso e fugitivo, e sobretudo a passagem com a prostituta Saraghina - vão tomando a dianteira. Elas dão tom ao filme. Se Fellini prosseguisse por aí, seria freudiano. 8 1/2 está a um passo de ser uma psicanálise em cena.

Mas as evocações se turvam na fantasia. A memória não está livre da imaginação. Há cenas de transição - como quando ele se vê numa espécie de cemitério, e há sobretudo cenas de pura imaginação. Três se destacam. Uma abre o próprio filme. É quando Guido, guiando um carro, condutor de seu rumo, - autista, poderíamos dizer, se quiséssemos empregar o belo nome italiano para o motorista, mas que nas outras línguas latinas expressa como que a verdade do dirigir um veículo, isto é, o seu autismo, a sua indiferença ao outro - , é tragado do carro por uma força insuspeita, que o lança aos ares e suscita sua crise. É a crise de criação, que faz o cineasta voar e despencar. O filme realizado decorre dessa fantasia que quebra a vontade de fazer um filme com começo, meio e fim. O começo do filme $81 / 2$ está na impossibilidade de se ter o começo do nono filme.

Uma segunda cena de imaginação, podemos dizer pura, é a do harém de Guido. Ele consegue, aparentemente, ter o que deseja: uma esposa que cuida de tudo, e um conjunto de mulheres bonitas com quem faz sexo. Vale a pena notar que o cerne desse pequeno episódio, desse filme dentro do filme, é o banimento, para o andar superior em que estão confinadas as concubinas esquecidas, de uma jovem que acaba de completar trinta anos: velha demais. É curioso, até porque ela não parece mais velha - ao contrário, mais jovem - do que algumas que ficam. Mas essa punição dá início à revolta, que derrubará o poder do macho. A cena, que começa parecendo real, se revela um sonho que, aliás, vira pesadelo, pelo menos para Guido. Ele não consegue unir seus dois anseios, a esposa e a amante, ou melhor, as amantes.

Aliás, antes de chegarmos à terceira fantasia, falemos da amante de Guido. Esta é completamente vulgar. É apresentada assim. Mas, mais que a vulgaridade de suas vestes e gestos, há o estranho pedido que essa mulher, que trai o marido, faz ao amante: pede-lhe, justamente, que arrume um emprego ou um trabalho para o esposo. A passagem é curiosa. Permite duas interpretações, pelo menos. A primeira é que ela estaria indo para a cama com Guido a fim de obter uma vantagem para o marido, talvez com o conhecimento e o consentimento deste. Se não com o conhecimento prévio, pelo menos com seu consentimento posterior, porque é óbvio que, se Guido aceder ao pedido, o esposo traído entende- 
rá qual foi a moeda que lhe trouxe a vantagem. A segunda interpretação é que, infiel ao marido, ela the é porém leal. Dorme com outro homem, mas conserva um laço com o companheiro. Neste ponto, ela é a imagem de Guido, que dorme com outra mulher, ou outras, mas entende preservar o elo com sua esposa. É praticamente impossível dizer se a primeira dessas interpretações tem alguma base. Ela supõe uma história que continue, e que nos permita julgar se o marido é conivente - seja a priori, seja a posteriori - com o adultério da esposa. A segunda hipótese é mais plausível, porque pelo menos pode ser aferida a partir do filme mesmo, sem suposições a ele externas, mas de todo modo não exclui a primeira.

Porque a lógica com a qual Guido - ou Fellini - opera é a do terceiro não-excluso, ou do terceiro incluso (daí, por sinal, a inclusão da outra no casamento, ou das outras no casamento, no pequeno filme interno ao filme) - ou seja, uma lógica anti-aristotélica. Essa é a lógica de seu desejo. Neste ponto, ela reata com algo que sabemos pelo menos desde Freud, ou seja, que essa é a lógica do desejo. Daí, a terceira irrupção da imaginação pura no filme. Trata-se da seqüência final. Chama a atenção que essa cena se desenvolva cada vez mais como real. É provável que seja, mesmo, real, isto é, que em vez de ser um sonho ela efetivamente tenha realidade. As duas seqüências que comentamos acima são óbvias fantasias. Esta pode ser, ou não. Principia com um fracasso. O filme não terá lugar. $\mathrm{O}$ filme sonhado e planejado (e aqui vemos o contraste entre um filme que o autor sonha e aquele que o produtor planeja) não ocorrerá. Mas dá-se, na plataforma da qual os humanos partiriam para Marte, no fracasso de sua aventura terrena, uma festa.

No lugar do máximo fracasso - fracasso no filme e fracasso do filme - eclode a alegria. Esta inclui uma grande conciliação, que engloba a paz entre as duas mulheres rivais no amor ou no corpo de Guido. Nada é excluído. É surpreendente a oposição dessa cena ao final da Dolce vita (1960). Neste, uma menina virgem se deparava com um monstro encontrado no mar. A jovem vinha em oposição a quase tudo o que antes se tinha passado. Era pura, e a vida do anti-herói era falha, fracassada, quase suja. Uma virgindade impossível, uma pureza fora do alcance do personagem do filme, fechava a película do fracasso pois é disso que La dolce vita trata: das ilusões perdidas, do fracasso de quem queria ser artista, intelectual, homem íntegro e resulta apenas um jornalista vão, rodeado de paparaži $i$ e de gente fútil, desperdiçando o amor que lhe é oferecido.

Aqui, porém, a cena final é de um possível sucesso. O sucesso não está aqui, não é deste mundo ${ }^{3}$. Estaria em Marte, se o nono filme existisse. Estará aqui, dado que o filme deu errado, mas somente nos sonhos, na conciliação que o id propõe mas a realidade nega. E no entanto uma chave foi dada, logo antes, quando Claudia Cardinale chegou para rodar o filme. Na verdade, não há contraste entre a atriz e a personagem. Ela chega com o nome de Claudia. É ela mesma, a atriz. Mas o que diz se ajusta perfeitamente ao que ela faria, se fosse personagem de Guido. Este lhe conta que não haverá filme e lhe abre o coração. Claudia responde "Porque não sabes amar", e repete esta frase até torná-la um mantra. Guido resiste a essa sentença, mas a cena final de reconciliação talvez resulte, justamente, de ele perceber essa sua dificuldade aparentemente insuperável. Fica mais ou menos em aberto a questão: conseguirá ele a redenção, ou pelo menos uma saída para o desastre em que se meteu na vida afetiva e, por conseguinte (há que frisar esse por conseguinte, que não é nada óbvio, porque muitos criadores poderiam criar em meio a uma vida pessoal arruinada 
ou, simplesmente, neutralizada), na vida criativa? ou ficará nesse impasse, nessa antinomia definitiva e insustentável que não lhe permite saída a não ser pela fuga (seria essa a leitura do crítico, a essa altura enforcado e supomos enterrado) ${ }^{4}$ ? Evidentemente, optamos pela primeira possibilidade.

Fellini e Woody Allen são talvez, hoje, os grandes cineastas da memória. Depois que Allen deixou de tratar dos temas da incomunicabilidade, que fizeram as más línguas as dos críticos, mais uma vez! - verem-no como um "[Ingmar] Bergman dos pobres", ele reciclou-se numa temática que está mais próxima da de Fellini. No entanto, não seria correto dizer que sua grande questão seja a da memória. É antes a da identidade. Tornouse lugar comum afirmar que seus filmes, há bastante tempo, tratariam de uma personagem que seria o próprio Woody Allen; é curioso que isso tenha ocorrido após suas grandes criações, como Zelig (1983), em que justamente ele se nega qualquer identidade, mostrando-se camaleônico como ninguém; ora, a maior parte dos espectadores desse camaleão, desse vácuo identitário, acredita firmemente que seus filmes sejam obras altamente confessionais.

Este é o ponto em que Allen se aproxima de $8 \frac{1}{2} 2$ : Fellini nos perturba porque não sabemos o que é verdade, o que é ficção. Seu diretor se chama Guido e é representado por um ator que é Marcello Mastroianni (mas que, na Dolce vita, aparecia com seu próprio prenome, Marcello); ficção, portanto, embora um cineasta falando de um cineasta sempre faça pensar em confissão; mas, chave de tudo, ou cifra a tudo complicar de vez, Claudia Cardinale surge com o nome de Claudia. Foi-se delineando a partir daí um estilo de Fellini, com suas mulheres gordas, suas personagens meio monstruosas, meio ridículas, e músicas de Nino Rota, assim como há um estilo de Woody Allen, com sua personagem confusa e perdida: e no caso de Fellini algumas obras, como Intervista, embaralham habilmente o que é ficção, o que é confissão.

É claro que tudo isso pouco importa, de um certo ponto de vista; o poeta é um fingidor, todos o sabemos, e sua arte consiste justamente em fazer a verdade (deveras sente) surgir sob a forma de fingimento (finge que é dor a dor que deveras sente). Mas também é verdade que, de todas as obras de arte que já se fizeram, dos filmes até hoje rodados, e mesmo que os reduzamos à pequena proporção dos que são obras de mestre, são muito poucos os que perturbaram a relação entre verdade e ficção, ou se fizeram confessionais. Estamos na minoria (a pergunta sobre a verdade, a afirmação confessional) da minoria (as obras de qualidade). Como nossos dois cineastas tratam disso?

$81 / 2$ é o filme de uma crise. La dolce vita (1960) era a película de uma condenação. Quase tudo, nela, sentencia. Mas $81 / 2$ não tem mais as certezas que eram berradas à socapa, bradadas implicitamente, na Dolce vita. A crise não é decorrência do tempo decadente delineado nesse último filme. A crise é crise da própria certeza que fazia condenar e elogiar. Sem dúvida, trair a mulher não é elogiado em 8 1\%2. Mas, se Guido não é um herói, tampouco é o pulha que o jornalista da Dolce vita se mostrava. Não há mais a idéia de uma missão, de uma vocação, de uma profissão que o personagem trai. Não há mais anti-herói, porque tampouco há herói. O filme é o registro de uma falência, mas vai-se depressa 
demais quando se assume essa leitura moralista (e lembro a nota de Prado: aos moralistas, Fellini oferece a forca, antes de chegar seu filme-realizado sequer à metade). É a falência do moralismo. Se há um ideal em 81 2, é o do avô que foge com a bailarina. O adultério não é elogiável, o harém não é viável - mas o avô, que escapa da esposa insuportável indo-se com o circo, ele sim traz consigo uma promessa de felicidade, porque é ele quem salva a neta da fogueira prometida às mártires ${ }^{5}$.

Mas o próprio da crise, ou da crise como se dá em 8 1/2 (mas não na nossa experiência histórica de brasileiros, num país que vive na crise desde que me conheço como gente), é que ela comece e termine, mesmo que seu término não represente uma solução comme il faut. Depois de 8 1/2, não haverá outra crise felliniana deste porte. Já Allen inicia uma carreira toda de crise. Ele reside na crise. A crise lhe sorri, ela é sua identidade. Ou pelo menos é o que sente seu público. Ouvi um dia, no cinema, enquanto assistia a um filme seu, um rapaz de classe média dizer à namorada, entre rindo e revoltado: "Mas é ele, ele está falando dele mesmo!’ Duas coisas me impressionaram: primeira, que esse espectador se fiasse assim nas aparências e confundisse, com a personagem, o autor-ator; segunda, a mistura de gargalhada (as gags eram boas, a sala ria) com indignação (como pode alguém ser tão louco assim? E tão louco por quê? Louco de se expor desse modo, quando deveria calar suas loucuras - ou louco de ser assim? Louco de ser ou louco de se apresentar?). Confesso que algum tempo depois, lendo uma entrevista de Woody Allen, vi que ele assumia tratar de si mesmo; enganei-me, então, ao me impressionar com a ingenuidade do meu espectador, que na verdade acertava, ao ver as aparências pelo que são; com isso vi, em sua risada irritada, uma percepção acurada: louco de ser desse jeito ou louco de mostrar seus podres? A loucura diz respeito ao que se é ou ao que se conta? Ela é da ordem do ser ou da ordem do discurso? Se é da ordem do ser, qual deformação produz essa má ontologia? E, se é da ordem do discurso, o que conduz a uma fala que se pauta por dois requisitos dificílimos, primeiro, o de falar sobre si, segundo, o de dizer a verdade? - encontro de requisitos que é bastante improvável, bem o sabemos.

A crise em Woody Allen é uma dialética sem Aufhebung. Tese: o principal personagem masculino ama alguém, é feliz, tudo ou quase tudo parece ir bem (Manhattan, Poderosa Afrodite e tantos outros). Antítese: a partir do nada, sem nenhuma razão mais forte, ele passa a procurar o que não tem, o que não é, e com isso põe em risco - ou mesmo destrói - o que antes tinha. Só que não há síntese. Seria de se esperar, se estivéssemos modulados por Hegel ou pelo menos por um progressismo menos culto, menos filosófico, que ao final se produzisse um encontro entre as tensões, uma superação dos conflitos, aquilo que Jean Wahl exprimiu de maneira tão admirável quando traduziu o verbo aufheben como surprimer $^{6}$ - mas não acontece nada disso.

Há uma síntese em 8 1/2, um salto qualitativo? Ao contrário de Allen, o filme encerra a crise, isto é, a partir daí o cineasta Fellini será diferente e não voltará a passar por crise tão aguda. Há, então, salto. Em Allen, não há. Deparamo-nos nele, filme após filme, com um drama que não dá mais para chamar apenas de incomunicabilidade, como se fazia com Bergman, mas que é - embora engraçado, geralmente - irredutível, insuperável. Esses 
adjetivos resumem bem o que é o pecado máximo contra a dialética, não por acaso o único pecado que na religião cristã aprendi que era imperdoável, o de não crer na infinita misericórdia de Deus: porque a Aufhebung é essa esperança de que, do conflito mais áspero, algo haverá de sair de positivo. Mas o salto felliniano não é esse salto otimista ${ }^{7}$. É uma mudança de plano, mas que só perceberemos a posteriori, alguns anos depois, quando ele realizar seu(s) filme(s) seguinte(s). A ferida se curou, talvez, mas não a vimos. Não sabemos como se deu o processo de superação. Vimos um filme que terminava em fracasso - em confissão de não se poder fazer o filme sonhado - e depois disso, anos passados, percebemos que aquele fracasso se converteu em sucessivos sucessos. Por quê? A única explicação plausível é que Guido descobriu que não realizaria seus ideais e aceitou não haver síntese, não haver solução, passando então tudo o que era tragédia em sua vida, em sua obra, para o registro bufo, do palhaço que conduz a cena ajudado pela música impagável de Nino Rota.

A solução é não haver solução. A tragédia some quando é levada até o fim e se vê que nela há, talvez, um erro de base: porque há tragédia quando duas posições antagônicas são, ambas, legítimas, e não é possível se chegar a uma síntese entre elas (para continuarmos falando como Hegel); ora, por que esta constatação nos conduziria ao desespero (a tragédia) e não, simplesmente, a desistir de procurar uma síntese que não pode advir? Tal desistência pode substituir o pranto pelo riso. A condição humana, sem sentido: qual máscara queremos dar a essa proposição, aquela que tem a boca para baixo ou aquela que abre a boca para cima? Tudo é teatro, tudo é representação, só nos cabe escolher entre a tragédia grega com seu massacre - que nos tempos atuais seria interiorizado, em vez de exteriorizado, mataria pela depressão e não pela espada - e a comédia. Na verdade, nem é uma escolha: se acreditarmos que existe um sentido - mas que não podemos aceder a ele - estaremos no plano da tragédia, que é o da crença num Deus escondido, numa perfeição que nos escapa mas, sim, está pressuposta; já a comédia tem um certo ateísmo de princípio: rir de nossas misérias significa que não acreditamos na beatitude, que podemos até admirá-la, desejar que ela existisse mas, dado que tudo indica não serem as coisas assim, não temos de passar a vida sofrendo porque não temos o que não há.

Serão épocas diferentes? Fellini pode mal falar em psicanálise, mas está criando no tempo em que Freud - um Freud mais ou menos ortodoxo, da IPA -, Jung, Reich dominam a cena psicanalítica. Pelo menos Freud e Reich, como então são vistos, prometem a cura. Data dessa época um dos mais espantosos fracassos do cinema, que é um filme dirigido por um dos dez ou vinte maiores cineastas da história - John Huston - e com roteiro, o que quase sempre se esquece, assinado por um dos três maiores filósofos do século passado, Sartre - que é Frend além da alma ${ }^{8}$. Neste filme é claro que os sofrimentos da psique se tratam e se curam, uma vez encontrada a causa, que se chama trauma. Durante muito tempo, foi essa a idéia predominante sobre a análise. Ela foi criticada severamente e, em nossos tempos em que o Freud ortodoxo cedeu bastante de seu espaço a Lacan, enquanto Reich e Jung deixavam de vez o campo da psicanálise para irem fazer outra coisa, cada vez se espera menos de uma análise. Uma das versões lacanianas disponíveis propõe, inclusive, que não seja possível mudar nada do que sofremos: só podemos nos responsabilizar pelo que somos, isto é, aceitá-lo. 
Fellini não acredita na cura do trauma - e por conseguinte no encontro de um sentido -, nem na completa impossibilidade de sua cura, no seu caráter por princípio insuperável. Allen é mais da não-cura, talvez esteja mais perto de Lacan. Mas ambos riem ou fazem rir. Não há tragédia. Não que se encontre o ponto de vista universal, que tudo reconcilia; mas é que a comédia humana faz rir. É um riso talvez mais catártico o de Fellini porque, embora não supere, pelo menos - graças em boa medida a Nino Rota -, põe a tristitia fora de combate. É talvez mais paradoxal o riso de Allen, porque só não caímos na tragédia devido a uma sucessão de efeitos de distanciamento, quase brechtianos, dos quais o mais forte é a própria constituição do ator-diretor como um clown: como, tornando-se impossível a tragédia, resulta impossível identificar-se com o herói trágico, rir dele (não mais herói, não mais trágico) é a saída.

Aqui, uma palavra sobre a diferença entre o riso e a tragédia. Uma teoria a respeito pode, alternativamente à hegeliana, juntar três autores. O primeiro é Stendhal, que diz em Racine e Shakespeare (1823) que podemos rir de um moço que cai na rua mas, se ele tiver a presença de espírito de fingir que manca, nosso riso de pronto cessa. O segundo é Rousseau, que explica essa situação: é que, desde que sentimos que houve um sofrimento de fato, e não apenas algo risível, nos identificamos com o ser vivo que sofre. Rir de alguém exige então que a identificação com ele, ou melhor, com sua dor seja barrada. Se e enquanto for possível identificar-se com a tristeza de alguém, não riremos. Inversamente, Brecht quer a todo custo impedir que nos identifiquemos com suas personagens. É célebre o momento em que Mãe Coragem, que sacrificou todos os valores e fez de tudo para salvar a família no período de mais sofrimentos que já viveu a Alemanha ${ }^{9}$, toma conhecimento da morte de seus filhos; estamos a ponto de despencar no choro; uma bandinha então irrompe no palco, com uma música alegre: fomos salvos, pela euforia ou pela boca que ri, de nos identificarmos. Assim, a tragédia, o sofrimento e a identificação formam um grupo, enquanto a comédia, a alegria e o distanciamento formam outro.

Allen consegue impedir a tragédia de eclodir no instante imediatamente anterior a seu momentum. Ele exclui o trágico, pelo riso, graças a sua bufonaria, isto é, fazendo-se alguém com quem é impossivel nos identificarmos. Por isso o rapaz que vi no cinema estava tão indignado com ele: como pode alguém fazer-se tão ridículo, como pode alguém fazerse um outro com quem é impossível sentir qualquer solidariedade, qualquer sentimento de comum pertencimento a uma espécie, um Outro radical, um outro de quem se ri e a quem, em circunstâncias extremas que eu talvez exagere, se poderia até massacrar - como pode alguém ser tão radicalmente outro, tão radicalmente judeu? É neste sentido que Allen faz humor judaico. Não é apenas o repertório. É a afirmação radical da alteridade. É a afirmação de que o laço social, a solidariedade ou mesmo a piedade para com ele se faz impossível. Ele faz tudo errado. O próprio casamento com a enteada, com alguém que era na prática sua filha, ainda que não tivesse o seu sangue: há algo mais errado do que isso? Ou em Harry se desconstruindo e, a cada etapa, acumulando mais erros e mesmo delitos? Por isso, não é que Allen acredite ou não acredite na cura. No fundo, isso tem menor relevo. O que conta é que ele talvez não a deseje, talvez não seja capaz dela. Com isso, sua tragédia se torna nossa comédia.

Aqui, a diferença de Fellini: para este, a comédia nos une. A comédia é potente laço social. Rimos todos a um só tempo, numa platéia: sentimo-nos parte de uma comunidade. 
$\mathrm{Na}$ televisão, os programas de humor muitas vezes têm risadas gravadas - porque rir sozinho é difícil, é quase uma transgressão. Isso matiza, pelo menos, o que escrevemos um pouco acima. Dissemos, há dois parágrafos, que a comédia distancia e a tragédia identifica. Mas há um cômico que agrega e congrega. É o de Fellini. Woody Allen faz outro tipo de comédia. É uma comédia só para o espectador. A tela nos separa radicalmente, e não adianta que na Rosa púrpura do Cairo ela se torne ponto de passagem da espectadora, vivida por Mia Farrow, para o mundo das imagens: na realidade, não.

Há algo sinuoso, talvez insidioso, no roteiro que segui neste artigo: pouco tratei de literatura e de arte, e da memória falei num sentido específico, que é o da confissão - e, ainda mais precisamente, na medida em que a confissão faz ou diz uma identidade. Aceitei um convite e no entanto o cumpri apenas em parte, seqüestrei o prometido. Acabou-se, dizem, a histeria; mulheres não enlouquecem mais em decorrência da rainha Vitória e de seu we are not amused, com o qual ela respondia quando ouvia alguma piada mais maliciosa ${ }^{10}$. Acabou-se, vimos, a esperança da cura pela psicanálise: os psicanalistas não prometem mais resolver, encontrar a chave que depois fará tudo desabrochar-se. Vivemos em meio a perversos, que fazem questão de infringir a lei, o contrato, a promessa. No mundo achatado pela igualdade diante da mídia, alcança mais facilmente sua dose de fama quem quebra a regra. Burlei levemente meu compromisso, e com isso paguei o que é devido aos tempos. Porque, na verdade, literatura como arte da memória permitiria outros tratamentos, mais apropriados: por exemplo, ver como a literatura se constrói como arte da memória, o que seria muito interessante para um leitor de Frances Yates e/ou do barroco; ou lidar com o jogo de gato e rato que é ínsito a toda confissão, misturando a verdade que lhe dá nervo com a simulação ou pelo menos a aparência de verdade que, também, lhe dá nervo.

Mas há outra razão, mais casta, mais confessável, que talvez permita que meu editor e meus leitores façam certa vista grossa a minha infração: é que Fellini não era de ver filmes. Impressionei-me quando li, certa vez, uma sua entrevista, na qual lhe perguntaram quais cineastas preferia, e ele respondeu: Não, não vejo filmes, leio romances e deles me vêm as imagens que coloco na tela. Woody Allen vê filmes. Talvez por isso se tenha tornado um cineasta mais ou menos francês, isto é, um realizador cujos filmes fazem cada vez mais sucesso na Meca dos espectadores, que é Paris (a Meca dos realizadores, é óbvio, continua sendo Hollywood, com suas imitações, das quais a mais notória é a Cinecittà à qual Fellini tanto deve). Uma das cenas mais famosas de Allen é quando, em Annie Hall, ele ouve um homem explicando as idéias de McLuhan, e se irrita tanto que chama o próprio comunicólogo para corrigir seu discípulo equivocado; pois bem, a cena se passa numa fila de cinema. Com freqüência, seus personagens vão a uma das salas célebres de cinéfilos de Manhattan. A própria maldade que consistia em analisar Allen a partir de Bergman tem a ver com isso: Allen é um cineasta ao quadrado, um cineasta sem inocência, porque todas as imagens, todos os planos se referem a outros que já forma filmados e exibidos; não que tenha de repetir, não que o estoque de imagens seja finito; mas o que faz o cineastaespectador é a dolorosa consciência de que sua arte tem uma história e de que ele conversa, sempre, com esse passado, essa tradição, essa linhagem. Não é essa uma questão de 
geração, porque décadas atrás Godard (Les carabiniers) e Truffaut (La nuit américaine e muitos outros), bem como esse ator querido do cinema francês, Jean-Pierre Léaud (tanto em Le dernier tango à Paris quanto no recente The dreamers, ambos de Bertolucci), encarnam bem essa leitura constante de filmes da qual parece depender o fato de se vir, depois, um dia, a rodar um filme.

Nada disso vale para Fellini. Ele põe em cena um cineasta, e talvez o mais poderoso - porque o mais em crise - dentre os cineastas já imaginados na tela. Mas esse realizador Guido não cita filmes, não pensa em cinema, não conversa sobre isso. Faz filmes (na verdade, não faz), mas seu fazer ou não fazer filmes nada tem a ver com vê-los ou com falar sobre eles. Fellini foi um cineasta escritor, não um cineasta espectador. Foi leitor de livros, mas ler não é o mesmo que ver. Por mais que um esnobismo já de meio século fale em ler filmes, nao foi o que Fellini fez. Estou exagerando, porque em outros filmes ele fará cinema, escolherá planos, conversará com e sobre atores; mas, nesta cesura estética ${ }^{11} \mathrm{em}$ sua obra que é 8 1/2, nada disso. O cineasta está em busca do sentido das coisas. E nisso lhe arde a memória: essa cesura, esse salto em sua obra depende de ele lidar com um passado que pesa como um trauma. Sim, a psicanálise aqui é aquela que nós conhecemos, aquela que está em Sartre e em John Huston, aquela que predominou até vinte ou trinta anos atrás: um evento traumático, situado na infância e significado sexualmente, cobra o seu preço ao longo de nossas vidas. A questão será então como trazer à luz este evento, dá-lo a conhecer pela palavra e, assim, superá-lo. Em nosso tempo, essa postura perdeu em glamour. Não há como superar plenamente o sofrimento em nós inscrito; não há como datar sua etiologia de um ponto preciso; não se extirpam complexos, não se faz cirurgia no id.

Esta é a época daquela que podemos chamar a trilogia de ruptura: 8112 , Giulietta, Amarcord (este, de 1973). Não são filmes em seqüência. Mas são os filmes do Fellini do meio, após as tragédias do início e antes dos exercícios do final. São os filmes de sua redefinição. Ele sofreu com La strada, condenou com La dolce vita, mas agora se põe em xeque. Giulietta tem muita fantasia: a imaginação prevalece, e no entanto uma cena pelo menos, a da pequena Giulietta ardendo como mártir cristã até que é salva - salva da salvação, da redenção espiritual - pelo avô, dialoga intensamente com 8 1/2, tanto que me ocorreu de trocar o episódio de filme sem problemas, apenas mudando Giulietta em Guido. Amarcord, "eu me recordo", é memória em estado bruto, ainda mais porque evoca um Fellini que é, mesmo, da Romagna e de Rimini. A melancolia de Amarcord, o abandono vivido em Giulietta, a crise do cineasta egocêntrico em 8 1/2 acabam formando um rico panorama das formas pelas quais se vive a memória quando se busca ajustar contas com ela. Podemos jogar com essas figuras - Giulietta poderia ser a esposa de 8 1/2, Guido poderia ser o menino crescido de Amarcord. Os papéis se trocam. Não é rico que um dos maiores criadores do primeiro século do cinema se tenha dedicado, com tanta atenção, quando estava "na metade do caminho de sua vida" ${ }^{12}$ de homem e de diretor, a meditar o papel da memória na construção de sua obra, de seu destino? 
Notas

${ }^{1}$ Ver meu artigo "Imagination and memory in Stendhal", Diogenes, Unesco, v. 51 (1), 2004, pp. 55-63 - em especial sobre a associação que Thomas Hobbes faz entre memória e imaginação.

2 Apenas a Capes, das principais agências de fomento, financia bolsas para artistas.

Quanto aos escritores (bem entendido, os que não são de não-ficção), os únicos apoios financeiros que recebem do mundo acadêmico consistem em raros programas de escritor-em-residência.

3 "Não é deste mundo" não é, aqui, uma proposição religiosa.

${ }^{4}$ Bento Prado vale-se deste ponto para, com humor, desqualificar a leitura que Roberto Schwarz faz do filme. Diz Prado: a postura de Schwarz é a do crítico do filme; ora, este foi enforcado antes de terminada a película; portanto, o juízo de Schwarz após o fim do filme é uma impossibilidade prática, porque é um morto que o profere.

Se considerarmos, contudo, que a morte de facto (ou de fictione) do crítico não elimina seu direito a julgar - a emitir uma sentença de além-túmulo, a fazer suas memórias póstumas - poderemos contudo dizer que as críticas "políticas", como as de Schwarz, medem-se a partir de um modelo, de um paradigma, cujo fracasso é precisamente o pressuposto do filme. 8 1/2, entre outras pressuposições, sustenta que faliu o mundo de sentidos prontos. A revolução é também ela um sentido pronto. A política tem esse papel.

O artigo de Bento Prado ("A sereia desmistificada"), publicado em 1968, foi reeditado em seu livro Alguns ensaios: filosofia, literatura e psicanálise (2a ed.), São Paulo: Paz e Terra, 2000.

${ }^{5}$ Aqui me dei conta de que misturei dois filmes, implantando em 8 1/2 uma cena de Giulietta dos espíritos (1965), outro dos filmes fellinianos da metade de sua vida, dos anos geniais que vão do final da década de 1950 até a metade dos 1970, em que memória e imaginação se fundem e confundem.

Deixo de propósito o erro no texto. Afinal, estou escrevendo sobre a memória, e a confusão ou o esquecimento fazem parte dela. Poderia dizer que há muito em comum entre Giulietta e 8 1/2, mas não vale a pena justificar um erro tão significativo.

${ }^{6}$ Mescla de supprimer, suprimir, de primer, dar excelência, e de sur, que realça o verbo primer. - Mas devo dizer que Sérgio Rouanet, a quem elogiei essa belíssima tradução francesa, protestou: aufheben, descobriu ele quando estudava alemão, se usava até para recolher a página de papel caída ao chão. São dois registros, o elevado e o comum. Precisará a filosofia ser dita em registro elevado?

Mas, para nós, de língua latina, pode o alemão alguma vez ser entendida como língua comum, fácil, do dia a dia?

${ }^{7}$ Evidentemente, esta leitura de Hegel não é única nem talvez a predominante. Devo aqui alguma coisa a Gérard Lebrun e a seu $O$ avesso da dialética, que traduzi para o português.

${ }^{8}$ Freud, the secret passion (1962).

${ }^{9}$ A Guerra de Trinta Anos.

${ }^{10}$ Mas o de que gosto mesmo na velha rainha é da história que David Cannadine relata: certa vez, em Bath, ela teria ouvido uma frase obscena; por isso, sempre que o trem real passava perto daquela cidade, Vitória mandava correr as cortinas. Produzia uma cegueira, para não ver os perigos do sexo. Cegava-se, como por sinal aquele grande ícone freudiano, Édipo.

${ }^{11}$ Aqueles que se lembram de Althusser reconhecerão, aqui, um eco da cesura epistemológica que, em seu pensamento, remetendo à filosofia da ciência, efetuava um corte entre a pré-história ideológica e a história científica de um autor: por exemplo, Marx.

${ }^{12}$ Para citar Dante e terminar este ensaio remetendo ao começo da literatura italiana. 